others, where the use of an actual cautery was productive of rapid and beneficiai results. Far be it from me to assume that any of the diseases, which apparently were subdued by its influence, would not have terminated in a manner equally favourable as if it had not been applied. Yet, seeing how fatally destructive such diseases frequently prove, and when so proving, how speedily the life is destroyed-knowing, also, that in every similar affection how anxious medical men are to produce a severe counter-irritation, from experience of its paramount importanceI felt justified in resorting to means which have hitherto been rarely employed, and of whose powerful influence we have little account, except in some isolated cases that have appeared in medical periodicals.

\section{CASE OF RECOVERY}

\section{FROM}

TAKING 'TWO DRACHMS OF ARSENIC.

By Jonathan Toogood, Esq.

W. R., aged 17, swallowed two drachms of arsenic, which he coarsely bruised with the end of a bottle at nine, p.m., on the $2 \mathrm{~d}$ of June, 1817, with a view to self-destruction. He repented, and made it known a quarter of an hour afterwards. Six grains of emetic tartar were immediately given and quickly repeated. Vomiting was soon excited, and briskly kept up, by copious draughts of warm water for two hours. Nothing was retained on the stomach during the night, and he complained of constant and severe pain in the stomach and bowels. He passed the night without rest, and on the following morning he complained still of great pain in his stomach and bowels, was very hot, with a frequent pulse and flushed countenance. He was copiously bled, and his bowels were relieved by injections, but nothing could be retained on the stomach until the erening after the application of a blister. Effervescing medicines, with opium, were then kept with difficulty, but he was not so much relieved until the fourth to make his recovery certain.

Bridgewater, December, 1841.

\section{ON QUACK COMPOSITIONS AND}

\section{PATENT MEDICINES.}

\author{
By JoH FosBRoke, M. D.
}

"Quackery has increased, is increasing, and must be diminished."-Bedpoes.

LOur correspondent's zeal in the good cause occasionally leads him away from the subject which he is discussting. We have, therefore, taken the liberty of pruning his article of some of its luxuriant offshoots.-Ens.]

Nothing that we have advanced concerning quacks and quackery, however comprehensive or forcible, can be complete, without a general overhauling of quack and patent medicines, which are great practical evils. Quackery, like sin, is very ancient. In the reign of the Emperor Valentinian, the medical practitioners of Rome, who were chiefly quacks, made laws to prevent the recovery of exacting and exorbitant charges and demands, particularly in the sale of secret compositions, which had prevailed in the empire. Circumstances in England and France are now precisely the same as formerly in Rome.
Mr. William Chamberlayne, in the beginning of this century, was a surgeon-apothecary at Clerkenwell, and the quaint and shrewd writer of Tyro Medicus, upon "The Duties of Medical Apprenticeship." About forty years ago he adverted to the mischief produced by the astonishing increase of the sale of patent and other empiric medicines; and, to show how much more the use of these injurious compositions prevailed in South than in North Britain, he observed, that the net amount, in one year, was not far short of $£ 14,000$ annually in stamp-duty, upon an augmenting sale of quack medicines and other injurious compositions, while in North Britain it returned not more than $£ 50$ per annum; and these exclusive of the duty on advertisements for the same.' -(London Medical and Physical Journal, 1801.)

Is this topographical difference owing to the greater proportion of sickness in the south, or to a greater degree of popular folly and credulity in the south than in the north? 'The people of the West of England, even to the east shore of the Severn, have been notorious, from Joln Wesley's time, for the love of quackery.

Dr. Cowan, of Reading, has rendercd good service to the profession and the anti-quackery cause, by his very able and efficient Reports on Quackery.-(Vol. viii., Transactions of the Provincial Medical and Surgical Association, p. 25., \&c.)

"The interests of government," he observes, "in empiricism were also, for the first time, accurately investigated, and it was shown, from unquestionable authority, that the revenue from quackery is less than $£ 50,000$ a year!!!" He then argues, that the great amount of the government profits is not one of the most tenable and practical objections urged by the opponents to all active measures. The obstacle of amount can no longer be regarded as insuperable or formidable.

"No efforts have yet been made to prevent, or even to curtail, the irresponsible and indiscriminate circulation of medicines; but that, by the stamp and patent regulations, this glaring abuse is legalised and encouraged; and, from the unequalled facilities which now exist for advertising, an injury upon the public health is inflicted, far greater than could ever be the case from the strictly personal, though unqualified, practice of physic." "The greatest, if not the most serious, obstacle to the procuring of the abolition of the patent medicines, at least in their present unrestricted form, is THE INERTNESS AND APATHY OF THE MEDICAL PROFESSION!!!!"-p. 78.

So it appears by Dr. Cowan's statement, compared with Mr. Chamberlayne's, that the sale of quack and patent medicines has increased, in nineteen years, full from $£] 4,000$ to $£ 50,000$ per annum, or by 3 and 1-8th.

Dr. Cowan has endeavoured, also, to form an estimate of the expenditure of the public in quack nostrums, and conceives it to be very high. He says that the increased sale may be deduced from taking an average of nearly five hundred stamped medicines, allowing for the greater numerical sale of the lowerpriced articles, and the multiplication of the sum so obtained by the annual number of stamps. Its accuracy is also confirmed by knowing the average value of the stamps, which clearly indicates the relative quantities sold of the cheaper and more expensive articles. Dr. Davies, of Presteign, says, "A town with a population of from 2,000 to 3,000 , having a weekly market, in a district wholly agricultural, sells at the least $£ 140$ worth of quack medicines yearly. This, I think, is $£ 40$ below the mark in many towns. I state the minimum."

Since the scarce corn and money year, 1838, a great number of the genteel, the middling, and the working classes, have left off applying to the physicians and general practitioners, and run to the shops for patent and quack medicines. Some druggists 
state that the sale of these forms now the principal part and profit of their business. The ignorant and credulous look into the newspapers and quack bills, read the puff, mark the name of the disease, whatever it may be-fits, convulsions, gripes, wind in the bowels, gravel, or what not,-and the remedy boasted for the cure of it, and buy it, and either take it themselves, or administer it to their children. They imagine the disease, and prescribe for the supposed name of it. Sometimes they give two or three quack nostrums for the name of ONE disease, and, mistaking both the real case and its causes, and all about it, do extreme mischief, and are obliged to send to a physician or general practitioner to remove the evil, if not fatal. Sometimes they borrow a dose from one of their neighbours, and swallow another man's medicine, without any regard to difference of age, sex, or dose. Sometimes they order a senseless farrago of their own prescribing, take it, and fancy it does them good. Sometimes they take that of the druggist's own composing. In many cases they call the common druggists " DOcTORs,"-for every medicaster and quacksalver is called a doctor by farmers, labourers, little tradesmen, operatives, and all illiterate persons, who are very numerous. We believe that, also, the applications to the country druggists to prescribe for the people, behind the counter and out of doors, has increased considerably of late, and that they have encroached more than ever on the general practitioners, and those blue-bottle-counter-druggist-apothecaries, who are qualified to practise solely as PIRE licentiates of the Hall, with a "show" in a small way.

It appears to us, from all we can gather from several neighbouring country towns, the sale of patent and quack medicines has increased greatly at the stationers' and druggists' shops, the newspaper offices, \&c., where they are vended. We have had a good government, but too procrastinating and tardy. It was entrusted, though it has since retired, with the discharge of that important and responsible dutyviz., the mode and choice of those detailed measures of REFORM, which the majority of the profession, in all 10,000, have called for, not to overlook the abolition of quack and patent remedies. The general practisers, in some measure, look for the abolition as the infliction of a loss on the druggists, who live chiefly by the sale of them, in return for the aggressions and encroachments of druggists upon their province and department in practical medicine and surgery. We also exhort the Home Department and representatives of the profession to take example by France. The compositions of all nostrums in France are divulged compulsorily to the Academy of Medicine, after which they get the license to sell them, if the ingredients are not injurious to the public health.

All affiches, placards, and advertisements, in newspapers, or on walls, or otherwise, and all quack bills, labels, \&c., recommending quack medicines, are by law issued on STAMPED paper (papier timbre), and so pay a tax to the interior government-a plan also worthy of adoption in this country-the stamped papers, with certificates from the authorities, containing the examination and declaration of the safe qualities of such quack nostrums and patent remedies, as are permitted for sale.

Nostrum-mongering is the principal form of rank quackery in France. But, before the nostrum can be publicly vended, the composition must be submitted to the Royal Academy of Medicine. If dangerous to the public health and safety, it is prohibited, under heavy penalties; so, also, if the law be secretly or openly infringed. If it be permitted, a license is given, and all placards by which it is made known are required to be sent to an appropriate bureau to receive the government stamp.

In this French arrangement there is the most just discrimination, and the rational liberty of the subject is not invaded. The quack may sell, and the dupe may buy. Law interferes only to protect the life, which, for self-advantage, the one cares not how he destroys, nor the other how he risks.

But Dr. Martin Sinclair, in his recent pamphlet on Medical Reform, states, that "the national income derivable from patent medicine stamps, licenses, \&c., as appears by Porter's Revenue 'Tables, amounts now only to $£ 32,000 \mathrm{per}$ annum for England and Wales," being an increase, as compared with Mr. Chamberlayne's statement, of $£ 18,050$ in forty years, and a reduction of Dr. Cowan's statement of its being less than $£ 50,000$ by $£ 18,000$.

Dr. Paris has rendered a service to the profession, by giving a list of patent and quack medicines and nostrums, and an analysis of them. He observes that he "cannot cease to deplore a credulity which should uphold and cherish so disgraceful and mischievous a system of treachery and imposture."

The profession in England is greatly indebted to Dr. Paris, in his "Pharmacologia;" Mr. Grey, in his "Supplement;" and Mr. Pareira, in his work on "Materia Medica," for the analysis and exposure of the composition and ingredients of many quack and patent remedies.

When we were in London, in 1828, we were told that within the last few years, up to that time, their sale had considerably diminished, and that the people looked more sharply into their merits than formerly, at least.

In 1807, thirty-four years ago, Dr. Hardy, of Dublin, in his comprehensive plan of medical reform, made these pertinent observations:- "It would certainly be a triumph of reason over weakness and credulity, if the advertisement of secret remedies, by which such myriads are daily cheated of their healths and properties, if not their lives, was interdicted. Individual liberty need not be trenched on. It is enough, if the legis. lature interposes to prevent deception being actively practised on the public, and that it has every right to do. But if these people will, nevertheless, afterwards penetrate to the recesses of the empiric, and will persist in swallowing the noxious or inert potions of the nostrum-mongers, we have no right whatever to interfere-"Si populus vult decepi, decipiatur."

Dr. Perceval laid it down so long ago as 1791, as one rule of medical ethics, for the guidance of the regular and honourable part of the profession, that the use of quack medicines should be discouraged by the faculty, as disgraceful to the profession, injurious to health, and often destructive even of life. Patients, however, under lingering disorders, are sometimes obstinately bent on having recourse to such as they see advertised, or hear recommended with a boldnes. and confidence which no intelligent physician dares to adopt, with respect to the means that he prescribes. In these cases, some indulgence seems to be required to a credulity that is insurmountable. And the patient should neither incur the displeasure of the physician, nor be entirely deserted by him. He may be apprised of the fallacy of his expectations, whilst assured, at the same time, that diligent attention should be paid to the process.

Thirty years ago, in 1810 , Beddoes addressed to the inert profession a series of very forcible objections to quack and patent remedies, stating the evils which they cause, and the best reasons for the discontinuance of their circulation and sale. Such is the effect of the national ignorance, credulity, and prejudice, that, -

]. Families, above the poorest families, are deprived of the necessaries of life, in consequence of money expended in the purchase of stamped and quack remedies. There are instances where people have sold the bed from under them, so great is the rage for quack medicines in some families.

2. "The quack himself is like a prostitute, who is not content to wait at home, in readiness to solicit 
already excited appetites, but roams abroad to practise all the arts of provocation." There is no end to the efforts and devices of quacks.

3 . The office of every country newspaper is an office for quack medicines; and often for nothing else. From the sale, the printer procures advertisements and pays himself.

'The fact is, that in all country newspapers, so far as I, who have had to do with the press, well know, they are always standing advertisements set up in what the printers call galleys, and inserted at lower charges than other advertisements.

Beddoes adds, that " every country stationer is stimulated by an enormous commission to pass them off." Besides the stationer, the retail druggist sells patent medicines; and in proportion as these quackeries are supposed cheap, and the compositions of the regular surgeon apothecaries, or blue bottle PURE apothecaries, have been less sought by the indigent public, the druggists say that they have got more by the sale of patent remedies, than by prescriptions or any other constituent of their businesses.

4. Beddoes observes "that the faith of that singular compound of folly and knavery," as Sir Walter very accurately defines, what is called " the world," in quack remedies, is kept up by the PEERS, JUDGES, and BISHOrs, who furnish certificates for the value of nostrums. To be sure they do! In an occult science like medicine, speaking of the credulity and folly of the rich, in matters of quackery, well has the refined and eloquent Mr. Pitt often said, "The desire of health seems to put all understandings on a level, the avaricious are duped by every bubble, the lame and unhealthy, by every quack!" which none but professional men can ever comprehend; it is notorious that the GREAT, the RICH, and LEARNED, have ever been the most strenuous supporters of quacks and quackery, imposture and delusion. There is a wonderful charm and fascination for those ignorant of the first principles of this science, in its being a speculative and uncertain art, in the mystery and secrecy of quackery, and the delusive hope it inspires ; but the same quack medicine that has flourished in darkness becomes despised when made known, because the veil is then removed from the imagination. Lord Bacon, with sound perspicacity says, "The people of all ranks judge of statesmen and physicians mostly by events, not by their intrinsic skill and ability, which they know nothing at all about."

$\mathrm{My}$ first and respected preceptor in anatomy, Mr. Joseph Green, states an argument in favour of the credibility of the asserted cures, which lords, ladies, bishops, and judges propagate by word of mouth, and even in certificates. It turns always on the old and often detected, but always powerful sophism, "Cum hoc, ergo propter hoc;" or, as it is better expressed than ever by Mr. Surgeon Green, FLATS mistake the "Id ex quo," for the "Id propter quo." I have exposed this sophism by word of mouth, and with the grey goose quill, all my professional life, but-

\section{"Man convinced against his will, Is of the same persuasion still."}

The false sylogism of the great and the little is this"The man was ill; he took this or that medicine; he got well again; and, therefore, his medicine cured him!" Cannot these people see that this sophism of theirs, hackneyed and trite as it is, from bad logicians, is a NON sEQuitur? That "he got well again," is a fact; but that he got well by the quack or the quack drug, does not follow; it is, therefore, a non sequitur, it is not a necessary effect! For, to use sound and genuine medical logic- "Might not the man have got well by the powers of his constitution, in spite of the remedy ? Might he not have got well if he had not taken the medicine at all? Are not either of these results just as probable as the asserted cure by the nostrum? Do we not, in public and private practice, see every day of our lives, that recovery and medicine going together are merely accidental coincidences, and the one is not always the effect of the other?"

From irrefragable statements of the rise and fall of all popular quacks in physic, all panaceas, and all nostrums, during these two or three last centuries in England, I have long since come to the conviction, and am fully prepared, with indisputable facts, to prove that no true dependence or belief whatsoever can be placed in either one or the other, quacks, nostrums, panaceas, or patent medicines, on account of authorities, confirmations, protestations, names of parties who, however respectable, educated, or refined -or however base, abject, and bribeworthy, have proclaimed and vouched for the efficacy of these gross and vain impositions in newspapers, pamphlets, and other modes of quack publicity. As to the protestations, testimonies, and direct evidence of all ranks and conditions of men, from the highest to the lowest, to confirm imposture, delusion, and villainy, proofs have never been wanting to confirm all three, but have been mostly numerous and positive in proportion to the total want of credibility to be attached to the imposture, and its power of performing the miracles mendaciously and fallaciously imputed to it. Medicine, its true principles, and practice, is a close, sealed, occult science and art, which an immense majority of mankind of all classes and distinctions know nothing whatsoever about, and of it have no rational conception. Every material, substance, and medicament, from the inert herb and common weed to simple water, having no properties beyond mere matter, have been at one period or another boasted up to the vain and empty nothingness of a great name, as the best remedy in the world for the inward bruises of all mankind. Indeed each has possessed in turn the same reputation, and produced the same imputed benefits as a panacea for the cure of every disease under the sun, and their imaginary virtues have been witnessed and attested by persons from the throne to the garret. As an able writer of sound judgment observes, "We are a people strangely given to quackery and novelty, and I make no doubt the cry would run as much in praise of hasty pudding, if half a dozen leading people, with a medicaster at the head of them, did but bellow out the wonderful cures it had performed." If the present age has been remarkable for the march of intellect-and if the schoolmaster has been abroad -if the grand inventions of skill have superseded manual labour, and, by producing excess and preventing human employment, proved a bane instead of a blessing, so has the march of humbug kept pace in religion and physic with the march of intellect and quackery, hypocrisy, and knavery, in an equal or greater degree.

Beddoes concludes as follows, in which it is needless to say we most cordially concur. "The advertising and sale of quack medicine," he says, "ought certainly to be suppressed. We would hope no panacea monger would stand up and plead the revenue alone as a reason for their permission, for they by no means contribute to lighten the general burden in proportion to the sums which they may cause to be paid for various stamps." "A scheme for the reform of medicine, without the abolition of quack medicine, is about as hopeful as one for making the rattle-snake harmless by leaving the venom-fangs in his jaws."

A certain northern professor has remarked of our English governments of the last half-century and above, that "they have looked upon this vile revenue as more valuable, in their judgment, than the health of the people, the prosperity of the regular profession, and the improvement of physic."

Chester, December, 1841. 